\title{
JUURNAL.RU
}

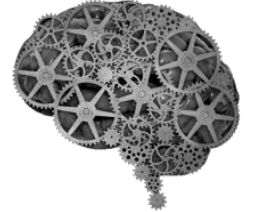

COMPANY GROUP "INTELLEKT"

Богданова О. В., Филатова Ю. Д. Донской Государственный Технический Университет Ростов-на-Дону, Россия

doi: 10.18411/lj2016-8-1-02

idsp 000001: lj2016-17-1-02

\section{Определение роли цвета и света в архитектуре}

Каждая эпоха формирует свои принципы гармонизации архитектурнопредметного ансамбля, свою меру связей в единстве художественного образа. В том числе для каждого архитектурного стиля характерно специфическое использование цвета и света в формировании архитектурной композиции.

Цвет в архитектуре - одно из средств архитектурной выразительности. Композиционные задачи в области цвета при возведении зданий, сооружений и архитектурных комплексов решаются путем использования собственного цвета строительных, или отделочных материалов, окрашиванием поверхностей в процессе возведения зданий и сооружений.
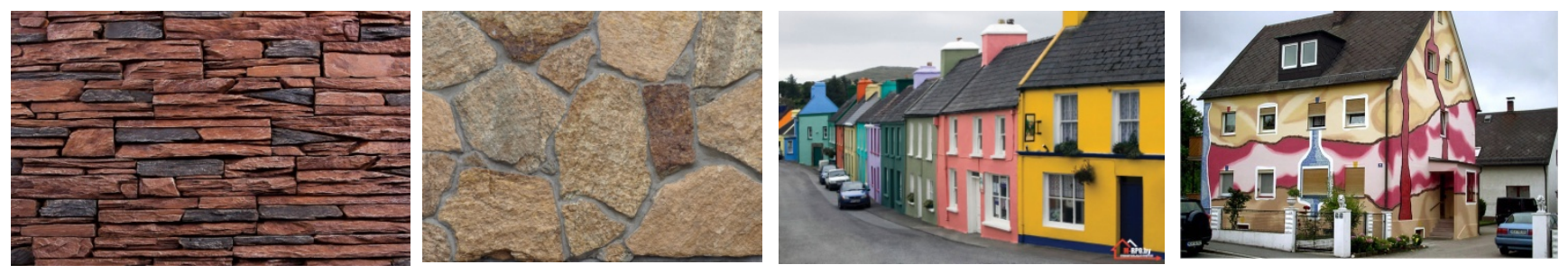

Выбор цвета определяется: назначением здания, габаритами здания, световым климатом района строительства, природным окружением, значением сооружения в общей композиции комплекса сооружений, характером архитектурных форм, тектонической структурой здания и др. В ряде случаев цвет обусловливается особенностями архитектурных стилей. Например, для фасадов русской архитектуры 12-15 вв. типичен белый цвет (Дмитриевский собор во Владимире), для сооружений 17 в.- сочетание красных кирпичных стен с белокаменными деталями и разноцветными керамическими фризами, вставками и др.(Церковь Живоначальной Троицы в Никитинках). Для русского 
барокко середины 18 в. характерны сочетания кобальтового голубого или фисташкового цвета с белыми деталями, позолотой, темной бронзой и т.д. ( Зимний дворец в Санкт-Петербурге)
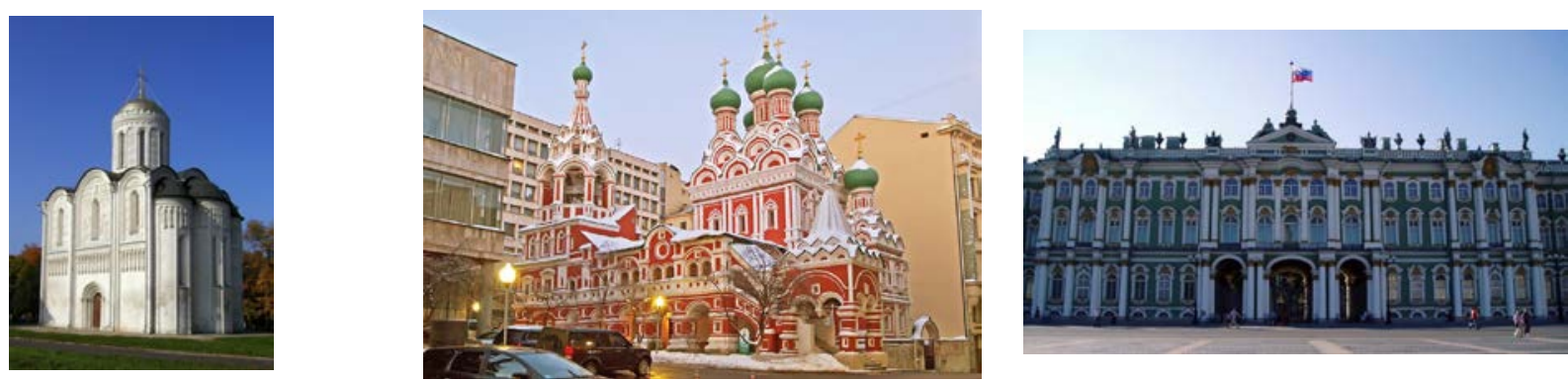

Посредством цвета можно разнообразить совершенно одинаковые дома, а также детали зданий, не удорожая их стоимости, придавать нарядность и привлекательность самым простым по форме сооружениям.

Если ширина улицы достаточно мала, а здание имеет большую этажность, то его цвет оказывает большое влияние на освещенность улицы, а так же на эмоциональную характеристику застройки. Улицы, образованные серыми фасадами зданий, при недостаточно высоком уровне освещенности выглядят мрачными, тусклыми, а образованные желто- белыми фасадами «солнечными» даже в пасмурные дни.

Принято считать, что красный цвет более теплый и, наоборот, голубой более холодный. Белый цвет является для многих олицетворением чистоты.

Проблема цвета в архитектуре тесно связана с вопросами освещения зданий и сооружений.

Размышления о свете, а также стремление им управлять уходят корнями в глубокую древность. Архитекторы прошлого широко использовали световую и темновую адаптацию и переадаптацию зрения.

В греческой архитектуре солнечный свет использовался как средство выражения тектоники храма. Светом и тенью утверждается его структура и прежде всего его ордер - конструктивная и пластическая основа греческого храма. Для зодчих барокко солнечный свет - средство создания живописных эффектов, соответствующих стилю архитектуры. Силуэтность храмов и ансамблей, их архитектурные формы, орнаментика, пластические приемы в русской архитектуре гармонируют с преобладающим диффузным освещением их облачным небом. 
Свет может облегчать глазу усвоение архитектурных масс и объяснять пространственные формы здания - одним словом, обладает пластической ценностью. Также свет обладает эмоциональной ценностью, поскольку распределение света и его контрасты могут создавать в душе зрителя определенное настроение, радостное или мрачное, уютное или торжественное, то есть поскольку

Говоря о количестве света, следует помнить, что архитектор может оперировать не только с естественным, но и с искусственным светом. Например, пространство апсиды, замыкающее светлые корабли древнехристианской базилики, погружено в темноту, однако строитель предусмотрел здесь эффект искусственного света, когда при мерцании свечей золото мозаик таинственно переливается в полутьме апсиды, создавая у молящихся ощущение мистической близости божества.

Любимый прием архитекторов барокко - затруднять путь свету, преломлять его или отводить в разные стороны, заставляя, таким образом, свет выхватывать из темноты как бы случайные куски пространства.

Сейчас архитектурное освещение распространено в больших городах, в частном секторе и на объектах коммерческой недвижимости. Власти многих городов, как в России, так и в мире осуществляют целевые программы по ночной подсветке объектов, представляющих историческую и архитектурную ценность.

Для создания выразительного архитектурного облика здания при разработке освещения необходимо учитывать несколько аспектов:

- расположение и роль объекта в городском ансамбле;

- композиционные особенности объекта - размеры, структуру, архитектурный стиль, а также фактуру и цвет облицовочных материалов;

- направление и расстояние, с которого может наблюдаться объект.

- существующее освещение территории, паразитная засветка от опор уличного освещения, наружной рекламы.

- архитектурный стиль освещаемого здания. Дизайн освещения должен гармонично вписываться в общий стиль здания. 

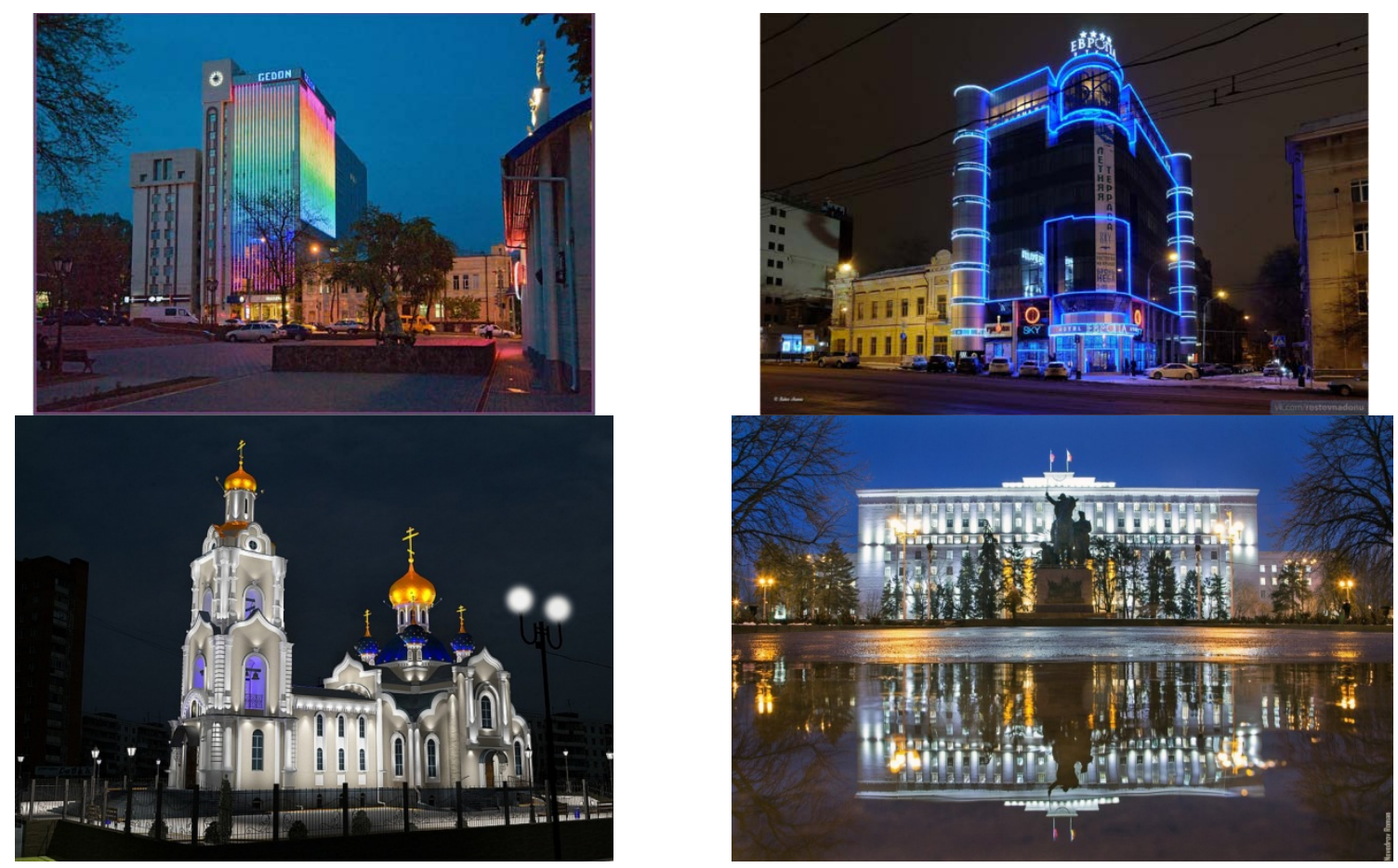

Таким образом, задача цвета и освещения - помочь человеку сформировать правильное восприятие пространства, архитектуры и атмосферы. При этом учесть множество факторов, самые простые из них - множественные эффекты теней и отражения.

\section{Литература:}

1. СП 52.13330.2011. Естественное и искусственное освещение. Актуализированная редакция. СНиП 23-05-95*. Издание официальное. Москва 2011

2. Алексеев С. С., Цвет и освещение. Общие проблемы, в кн.: Очерки теории архитектурной композиции, М., 1960

3. Келер В., Лукхардт В., Свет в архитектуре. Свет и цвет, как средства архитектурной выразительности, пер. с нем., М., 1961 